\title{
RECIPROCITY AND INTERCHANGE IN THE SOCIAL RELATIONSHIPS OF WILD MALE CHIMPANZEES
}

\author{
by
}

\author{
DAVID P. WATTS ${ }^{1,2)}$ \\ (Dept. of Anthropology, Yale University, P.O. Box 208277, New Haven, CT, USA)
}

(Acc. 30-XI-2001)

\begin{abstract}
Summary
Social relationships in nonhuman primates result from investments that individuals make while pursuing fitness-maximizing strategies. These strategies sometimes include social exchange, either reciprocity (exchange of the same acts) or interchange (exchange of different acts). Individuals in many species may negotiate for services in biological markets, particularly grooming and agonistic support. They also may compete for access to valuable social partners. Abundant evidence for reciprocity in grooming and in support and for competition over partners exists, notably for females in some cercopithecines. However, evidence for interchange of grooming and support is scarcer, and apparent interchange may be a byproduct of correlations between grooming or support and some third variable (e.g. dominance rank). Chimpanzees have been prominent in discussions of social exchange, especially because male chimpanzees cooperate in many ways. Most analyses of interchange have used data on captive chimpanzees; these provide good evidence for reciprocity, but ambiguity with regard to interchange. Data on an unusually large chimpanzee community at
\end{abstract}

\footnotetext{
1) Author's e-mail address: david.watts@yale.edu

2) I thank Makerere University and the Uganda Wildlife Authority for permission to work in Kibale National Park. I am indebted to G. Isibirye Basuta and J. Kasenene for permission to work at the Makerere University Biological Field Station, and thank them and the Field Station staff for logistical support. My research at Ngogo has been in collaboration with John Mitani, and one could not hope for a better collaborator. A. Magoba, G. Mbabazi, G. Mutabazi, L. Ndegezi, and A. Tumusiime provided invaluable research assistance in the field, and I thank J. Lwanga for his skilled coordination of the Ngogo Chimpanzee Project and for imparting some of his knowledge of the forest to me. My research has been supported by grants from The L.S.B. Leakey Foundation, The National Geographic Society, and Yale University. I thank Joan Silk for the opportunity to contribute this paper to the symposium that she organized and for organizing the publication of those papers. I thank Bill McGrew and an anonymous reviewer for useful comments on an earlier version of the paper.
} 
Ngogo, Kibale National Park, Uganda, strongly support the argument that social exchange is prominent in social relationships among males. Males at Ngogo show reciprocity in grooming and support. They also interchange grooming given and support received, as well as grooming received and support given, independently of reciprocity in grooming and support and of correlations of support and grooming with dominance rank. However, most cooperation in contests with third parties took low risk forms (e.g. both participants outranked their opponent). In this, males at Ngogo resemble captive chimpanzees and female cercopithecines. Reciprocity and interchange in this context may be important in the maintenance of social bonds between males, and in attainment and maintenance of high dominance rank, but probably represent mutualism, not reciprocal altruism.

Keywords: chimpanzees, social relationships, reciprocity, interchange, grooming, coalitions, mutualism.

\section{Introduction}

Kummer (1978) proposed that social relationships in nonhuman primates are the outcomes of investments that individuals make as they follow strategies to increase inclusive fitness. 'Investments' refers to partner choice for association or grooming, allocation of grooming among partners, provision of agonistic support, and so on, and the value of potential social partners varies with the fitness benefits that relationships with them can bring. In this influential perspective, primates often engage in exchanges of social acts, including reciprocity (exchange of the same act) and interchange (exchange of different kinds of acts; Hemelrijk, 1990a). Interchange of grooming for agonistic support may be particularly important. This raises the possibility that relatively powerful individuals who can provide effective support - for example, high-ranking females in baboon (Papio spp.) and macaque (Macaca spp.) groups - are attractive grooming partners and that others compete to groom them (Seyfarth, 1977, 1980). Whenever individuals cannot forcibly appropriate valuable social resources from others, and the ability of others to provide these resources varies, they should compete for partners and negotiate about resource distribution in biological markets (Noë et al., 1991; Noë \& Hammerstein, 1994). Market effects, like 'shopping' for alliance partners by male baboons (Noë, 1992; Noë \& Sluijter, 1995), may be common among primates, many of which seem to use knowledge about variation in partner quality and about third-party social relationships extensively when developing and maintaining their own social relationships (Harcourt, 1989, 1992; Cheney \& Seyfarth, 1990; Cords, 1997). 
In primate species that form multi-female groups and in which females are philopatric and establish clear dominance hierarchies ('resident-nepotistic' species; Sterck et al., 1997), grooming among females is common and females form differentiated grooming networks. In some cases, females also frequently form coalitions with relatives and non-relatives. Much of the theoretical and empirical focus on interchange of social acts in nonhuman primates has been on whether females in these species reciprocate grooming and support, compete for grooming partners, and trade grooming and coalitionary support (e.g. Seyfarth, 1977, 1980; Hemelrijk, 1990a, b; Perry, 1996; Barrett et al., 1999; Henzi \& Barrett, 1999; Schino, 2001). A recent metaanalysis of data on resident nepotistic species of Old and New World monkeys (Schino, 2001) provides strong support for the hypotheses that females show reciprocity in grooming and in coalition formation and that they compete for grooming partners. However, as Schino (ibid.) and Henzi \& Barrett (1999) note, support for the hypothesis that females in these species interchange grooming and support is weaker ( $c f$. Hemelrijk, 1990b; Matheson \& Bernstein, 2000). Also, apparent interchange of grooming and support may be a byproduct of causal relationships between both of these variables and some third variable. For example, Hemelrijk (1990b) showed that correlations between grooming given and support received, and between grooming received and support given, in a group of vervet monkeys (Cercopithecus aethiops) were non-significant when the effects of dominance rank were controlled. Individuals showed reciprocity in grooming and preferentially groomed high-ranking partners, while high-ranking individuals supported others at high rates.

Chimpanzees (Pan troglodytes) also figure prominently in discussions of reciprocity and interchange among primates, for two major reasons. First, benefiting from social exchanges may be cognitively demanding. Observations under naturalistic conditions imply, and many experiments show, that chimpanzees have complex cognitive capacities, including some capacity to assess numerosity and to judge proportions (Woodruff \& Premack, 1981; Boysen, 1997; Biro \& Matsuzawa, 2001). Such quantitative abilities could help in tracking social exchange balances (de Waal \& Luttrell, 1988). However, individuals could instead maintain favorable cost-to-benefit ratios simply by tracking the relative frequency with which they direct acts towards others and receive acts from them, a less demanding cognitive task (Hemelrijk, 1990a; Hemelrijk \& Ek, 1991). Also, bookkeeping is unnecessary if all 
participants in an act of social exchange or a cooperative interaction gain net benefits (de Waal \& Luttrell, 1986; Chapais, 1992).

Secondly, chimpanzee males use notably complex tactics to compete and cooperate with conspecifics and can be considered 'male-bonded' (van Hooff \& van Schaik, 1994). Wild chimpanzees live in socially bounded, multimale, multi-female communities whose members form parties that vary in composition and duration, largely because of variation in the abundance and distribution of ripe fruit (Nishida, 1968; Wrangham, 1979). Males are typically more gregarious than females (Nishida \& Hiraiwa-Hasegawa, 1987; Pusey, 2000). They are also philopatric, but maternal relatedness does not have consistently strong affects on their social relationships with each other (Goldberg \& Wrangham, 1997; Mitani et al., 2000; Mitani et al., in press). Otherwise, relationships among males in the same community resemble those among female macaques in that they involve differentiated association and grooming networks and frequent coalition formation. Many, if not all, male dyads establish decided dominance relationships. Most males make much effort to achieve high dominance rank. Some dyads form alliances (i.e. repeatedly and consistently form coalitions with each other) that can facilitate these efforts, and alpha males may depend on allies to retain their positions (de Waal, 1982; Nishida, 1983; Goodall, 1986; Nishida \& Hosaka, 1996; Watts 1998). High-ranking males often gain disproportionately large shares of copulations (Tutin, 1979; Hiraiwa \& Hiaraiwa-Hasegawa, 1990; Watts, 1998), which can bring high reproductive success (Constable et al., 2001). Male-male grooming is relatively more common than grooming between males and females or among females (Goodall, 1986; Nishida \& Hiraiwa-Hasegawa, 1987), and it contributes to alliance development and maintenance (de Waal, 1982; Hosaka \& Nishida, 1996). Males sometimes cooperate in hunting, and they routinely share meat (Boesch \& Boesch, 1989; Boesch, 1994; Boesch \& Boesch-Achermann, 2000; Stanford, 1998; Mitani $\&$ Watts, 2001). Also, all the males of a community cooperate in competition with members of neighboring communities. This includes responding aggressively to neighbors encountered during foraging (Goodall, 1986; Boesch \& Boesch-Achermann, 2000; Herbiger et al., 2001) and deliberately patrolling territory boundaries to search for signs of neighbors. Patrollers may attack outnumbered neighbors, sometimes lethally (reviewed in Wrangham, 1999). 
Given the extent and importance of such cooperation (even at Taï, where male alliances influence dominance relationships less than in other populations; Boesch \& Boesch-Achermann, 2000), models of exchange and partner competition developed with reference to female cercopithecines ought to apply to male chimpanzees (Watts, 2000b). For example, males presumably have opportunities to benefit from the interchange of grooming and agonistic support (Hemelrijk \& Ek, 1991). However, most analyses of the exchange of social acts by male chimpanzees have concerned captive groups, notably that at the Arnhem Zoo, in the Netherlands. Hemelrijk \& Ek (1991) found reciprocity in grooming at Arnhem and de Waal found reciprocity in agonistic support there (de Waal \& Luttrell, 1988). However, de Waal (1978, 1982, 1984) stressed that males chose coalition partners opportunistically: when the community had a clear alpha male, males generally supported other males and females with whom they spent the most time in close proximity, but support frequency was not closely linked to proximity when the alpha position was unstable or undecided. Hemelrijk \& Ek (1991) also found reciprocity in agonistic support, but only during periods with no clear alpha male, and again stressed the opportunism of male coalition formation during such periods. They also found a significant positive correlation between grooming given and support received during periods with a clear alpha male, but this was a byproduct of two other associations. These occurred between grooming given and support given and between grooming received and support received: males supported those they groomed often, and also received support from those who often groomed them. Correlations between grooming received and support given were non-significant (ibid.). Hemelrijk and colleagues (Hemelrijk et al., 1992; 1999) also found little evidence for exchange between males and females that could affect male reproductive success directly. For example, no significant relationships existed between either male copulatory frequency (Hemelrijk et al., 1992) or paternity (Hemelrijk et al., 1999) and the frequency with which males groomed, supported, or shared food with females.

These analyses address important questions about chimpanzee social relationships, but we need comparable data from wild populations to assess whether the same relationships hold when community members are not constrained to associate permanently, as they are in captivity. Choice of partners with whom to associate is a fundamental tactic in the social strategies of wild chimpanzees (Newton-Fisher, 1999). A previous analysis 
of data on wild chimpanzees at Ngogo, Kibale National Park, Uganda showed reciprocity in grooming between males (Watts, 2000a). Males there also share meat reciprocally (Mitani \& Watts, 1999, 2001) and grooming is associated with several forms of cooperative behavior (e.g. frequency of joint participation in boundary patrols; Watts \& Mitani, 2001). In this paper, I review results of these previous analyses, and use much more extensive data from Ngogo to test seven hypotheses. These specifically concern social relationship among adult males, although possibilities for exchange between males and females also exist (e.g. one reason that males hunt may be that they can exchange meat for matings (Stanford, 1998), although data from Ngogo do not support this hypothesis (Mitani \& Watts, 2001)). These hypotheses are:

1) Males show reciprocity in grooming.

2) The attractiveness of males as grooming partners is positively associated with dominance rank ( $c f$. Watts, 2000b).

3) Males show reciprocity in agonistic support.

4) High-ranking males are attractive coalition partners.

5) Reciprocity in grooming and support is independent of the effects of male rank.

6) Males interchange grooming and agonistic support. This relationship is independent of reciprocity in grooming and in support; of any relationships between grooming and rank and between support frequency and rank; and of any association between grooming given and support given and between grooming received and support received ( $c f$. Hemelrijk \& Ek, 1991).

7) Males use grooming to gain tolerance from others or to appease them (de Waal \& van Roosmalen, 1979; de Waal \& Luttrell, 1986). I do not attempt a thorough examination of this hypothesis, partly because I lack some required data (e.g. controlled comparisons of grooming frequency in post-conflict contexts to grooming at other times). Instead, I use a subset of the data to examine whether the amount of aggression that one dyad member gives to the second is inversely related to the amount of grooming that he receives from the second, independently of reciprocity in grooming or interchange of support. 


\section{Methods}

\section{Study site and subjects}

I collected the data reported here at the Ngogo research site in Kibale National Park, Uganda, during six study periods (June-December, 1995; May-August, 1996; May-August, 1997; October, 1998-August, 1999; May-August, 2000; and May-August, 2001). Ngogo is in the central part of Kibale, about $10 \mathrm{~km}$ southeast of the better known Kanyawara research site and about $150 \mathrm{~m}$ lower in altitude. The Ngogo chimpanzee community uses an area about $35 \mathrm{~km}^{2}$ that consists mostly of mixed mature and regenerating forest transitional between lowland and montane evergreen forest. It also includes other, more minor vegetation types, such as Pennisetum purpureum grassland, some of which the chimpanzees use only infrequently (Butynski, 1990; Struhsaker, 1997). The chimpanzee community is the largest on record (Watts, 1998, 2000a, b; Mitani \& Watts, 1999; Mitani et al., 1999; Pepper et al., 1999; Watts \& Mitani, 2000, 2001; Mitani et al., 2000). It contained between 22 and 24 adult males, plus 14 to 17 adolescent males, over the time span considered here. The exact size of the community is uncertain, but, as of August, 2001, it also included about 50 or more adult and adolescent adult females and about 60 juveniles and infants, for an estimated total of 150 members.

\section{Data collection and analysis}

I observed the chimpanzees for 5,367 hours during the five study periods. This included 1,851 hours of focal data on male social behavior. During these samples, I kept longhand records of all agonistic interactions (including polyadic interactions) and grooming bouts in which focal individuals were involved and timed those bouts to the nearest 30 seconds. I kept running totals of grooming by each partner during bouts grooming bouts. I also collected alloccurrences data on grooming between males when I was certain that I could see all males in a given party, by continually scanning the males and noting the times at which they stopped grooming, switched roles, or switched partners, and I collected ad lib data on coalitions ( $c f$. Watts, 2000a, b; Watts \& Mitani, 2001). I used values for the total duration of grooming given and received per dyad in analyses of reciprocity and interchange. Most coalitions involved two or more males who jointly charge at or attacked other males, rather than interventions by third parties in ongoing conflicts. When coalition partners initiated aggression, I considered the male who initiated the attack to have received support from all others who subsequently joined him; correspondingly, those others gave support to the initiator. When three or more males jointly directed aggression at others, I scored a coalition between each dyad. For dyads that did not include the initiator, I also ascribed support given and received on the basis of the order in which they joined.

I assigned dominance ranks to males on the basis of the direction of behavioral acts and signals in decided agonistic interactions. I followed convention by assigning rank 1 to the alpha male, rank 2 to the beta, rank 3 to the third-highest ranking, and so on. This mostly meant that one male pant-grunted to a second, either in response to aggression or when one of the males approached the other. I also included interactions in which one male charged or lunged at a second, who fled or avoided the aggressor. In all study periods, some pairs of males did not have decided agonistic relationships. In these cases, I assigned the same rank to each male. 
When males intervene in ongoing dyadic contests, they can choose to support likely winners or likely losers (De Waal, 1978). Most coalitions at Ngogo did not involve such interventions; instead, they formed when two or more males displayed at or directed other aggression at third parties (Opponents) or when they jointly retaliated after Opponents displayed at them (either singly or as coalitions). When one male (the Aider) joined another (the Actor) in these circumstances or he intervened in an ongoing contest, several combinations of relative dominance ranks among participants were possible. For every trio of Aider, Actor, and Opponent in a polyadic interaction, I assigned the Aider and Actor to one of six categories: (1) Aider and Actor both outrank their Opponent; (2) Aider subordinate to Opponent, Actor dominant to Opponent or with equal rank; (3) Aider dominant to Opponent or with equal rank, Actor subordinate to Opponent; (4) Aider equal to Opponent, Actor either dominant to or subordinate (I combined these because very few cases involved Aiders equal to Opponents and Actors subordinate to them); (5) Aider, Actor, and Opponent all with equal rank or unresolved relationships; (6) Aider and Actor both subordinate to opponent.

I used Hemelrijk's (1990a) MATSQUAR software for analyses of reciprocity and interchange and to analyze the relationships of grooming and agonistic support to dominance rank. I used MATSQUAR Partial (Hemelrijk, 1990b) to analyze relationships between two social variables with third variables controlled (e.g. to examine the correlation between grooming given and support received with grooming received controlled). MATSQUAR is a matrix permutation program that calculates several indices of association between variables from observed dyadic values, then randomly permutes row and column values to generate sampling distributions against which to assess the significance of test statistics derived from the original data matrix. It avoids problems associated with the non-independence of dyads and with the fact that sampling distributions for dyadic values are unknown (Hemelrijk, 1990a). Matrices for grooming given and received and for support given and received were asymmetric actorreceiver matrices (Hemelrijk, 1990a; Watts, 2000a). To test hypotheses that these variables were related to dominance rank, I calculated correlations between these matrices and symmetrical hypothesis matrices in which entries were the ranks of the column males (Hemelrijk, 1990a; Watts, 2000a). I used $K_{r}$ tests, which give a multivariate version of Kendall's S statistic $\left(\operatorname{Tau}_{K r}\right)$ corrected for samples sizes and ties (Hemelrijk, 1990a), and used 5,000 permutations for each test.

MATSQUAR provides analyses of reciprocity and interchange at group level (Hemelrijk, 1990a). $K_{r}$ tests address the general hypothesis that individuals direct relatively more of a given act towards those from whom they receive more of that act, or another for which they exchange it, and direct relatively less towards those from whom they receive less. Such group level tests do not allow analyses of reciprocity within dyads (Silk et al., 1999). Male chimpanzees at Ngogo show striking variation in the balance of grooming within dyads, and several factors (e.g. whether males are allies) seem to influence this variation. However, analysis of within-dyad reciprocity is beyond the scope of this paper.

I combined data from the 1995 and 1996 study periods because the top of the male dominance hierarchy remained the same throughout these periods (Watts, 2000a, b). This meant that I tested each hypothesis five times. I used Fisher's combined probability test (Sokal \& Rolf, 1995) to assess overall significance of each test (cf. Hemelrijk \& Ek, 1991). 


\section{Results}

Frequency of dyadic combinations in coalition formation

Most (69\%) dyads of coalition partners involved males who both outranked their Opponents, and either the Aider or Actor was dominant to the Opponent in most other cases (Fig. 1). Fairly often (28\% of coalitions), aiders were subordinate to Opponents or had unclear relationships to them; in most of these cases, they joined Actors who outranked Opponents (Fig. 1). For example, male BA, who became the alpha male in 2001 but had previously been the ally of long-time alpha male MW, supported MW against male EL at times when his own relationship with EL was unclear, and TY, a middle-ranking male, sometimes supported LO, a high-ranking male who was briefly the alpha male between MW and BA, against males to whom he was subordinate. Cases in which Actors and Aiders both had equal ranks with Opponents or were both subordinate to them were rare (Fig. 1).

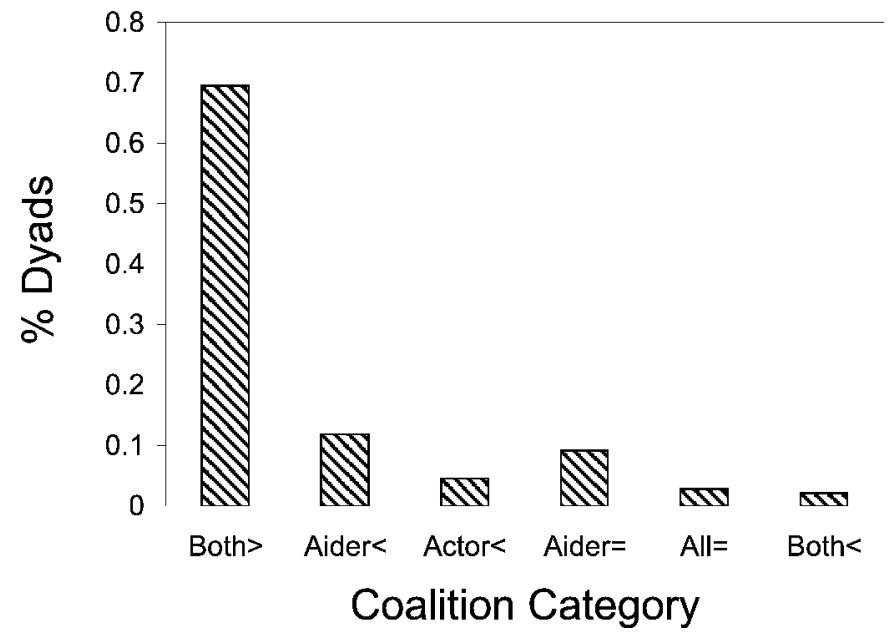

Fig. 1. Partner combinations, with respect to dominance ranks, in polyadic agonistic interactions. 'Both $>$ ' indicates that both coalition partners outranked opponent. 'Aider $<$ ' indicates that the male who joined a coalition was lower-ranking than the opponent, but the male he supported outranked the opponent or had equal rank. 'Actor $<$ ' indicates that male who joined the coalition supported a male who was lower-ranking than their opponent. 'Aider $=$ ' indicates that male who joined the coalition had a rank equal to the opponent's, while the male he supported had a rank either greater than or less than the opponent's. 'All =' indicates that all males had equal or unresolved ranks. 'Both $<$ ' indicates that both the male who joined the coalition and the male he supported were subordinate to their opponent. $N=885$ Aider-Actor-Opponent trios. 
Tests of hypotheses

The data supported all six hypotheses. Together, these results support the general hypothesis that social exchange, including interchange of grooming and support, occurs among wild male chimpanzees.

\section{(1) Males show reciprocity in grooming}

Analyses of grooming data from 1998-1999, 2000, and 2001 corroborated results of previous analyses of data from the combined 1995-1996 study periods and from 1997 that showed reciprocity at group level (Watts, 2000a). During all study periods, some males did not groom at all with each other and many others groomed infrequently, whereas grooming was common in some dyads (e.g. males BA and MW in all study periods). Figure 2 gives a representative illustration from 1998-1999. Males showed highly significant group level reciprocity in grooming in all study periods, and the combined probability value was highly significant (Table 1 , result 1a). That is, the relative amount of grooming that males gave to others was highly correlated with the relative amount that they received from them.

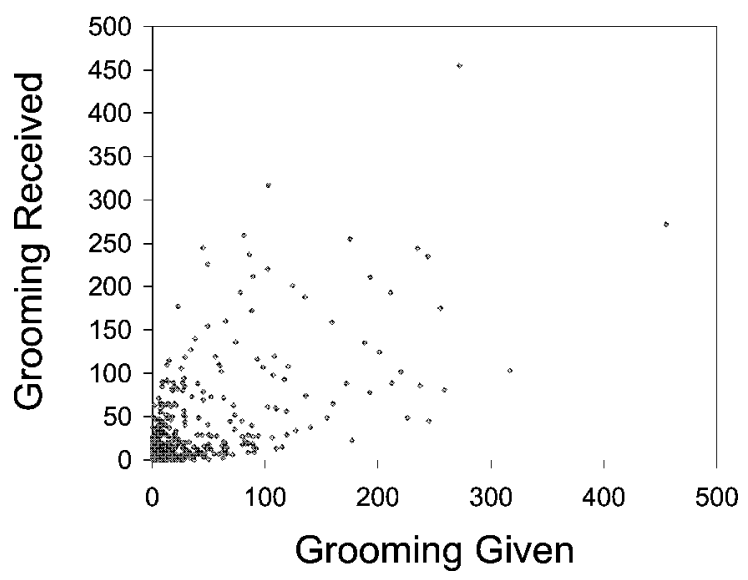

Fig. 2. An example of reciprocity in grooming: the relationship between the amount of grooming (in minutes) that one member of a male dyad gave to the other to the amount of grooming that he received from the other. Data are from the 1998-1999 study period ( $N=24$ adult males). Each symbol represents one dyad. The bivariate plot is for purposes of illustration only; the data were analyzed with non-parametric matrix permutation methods. 


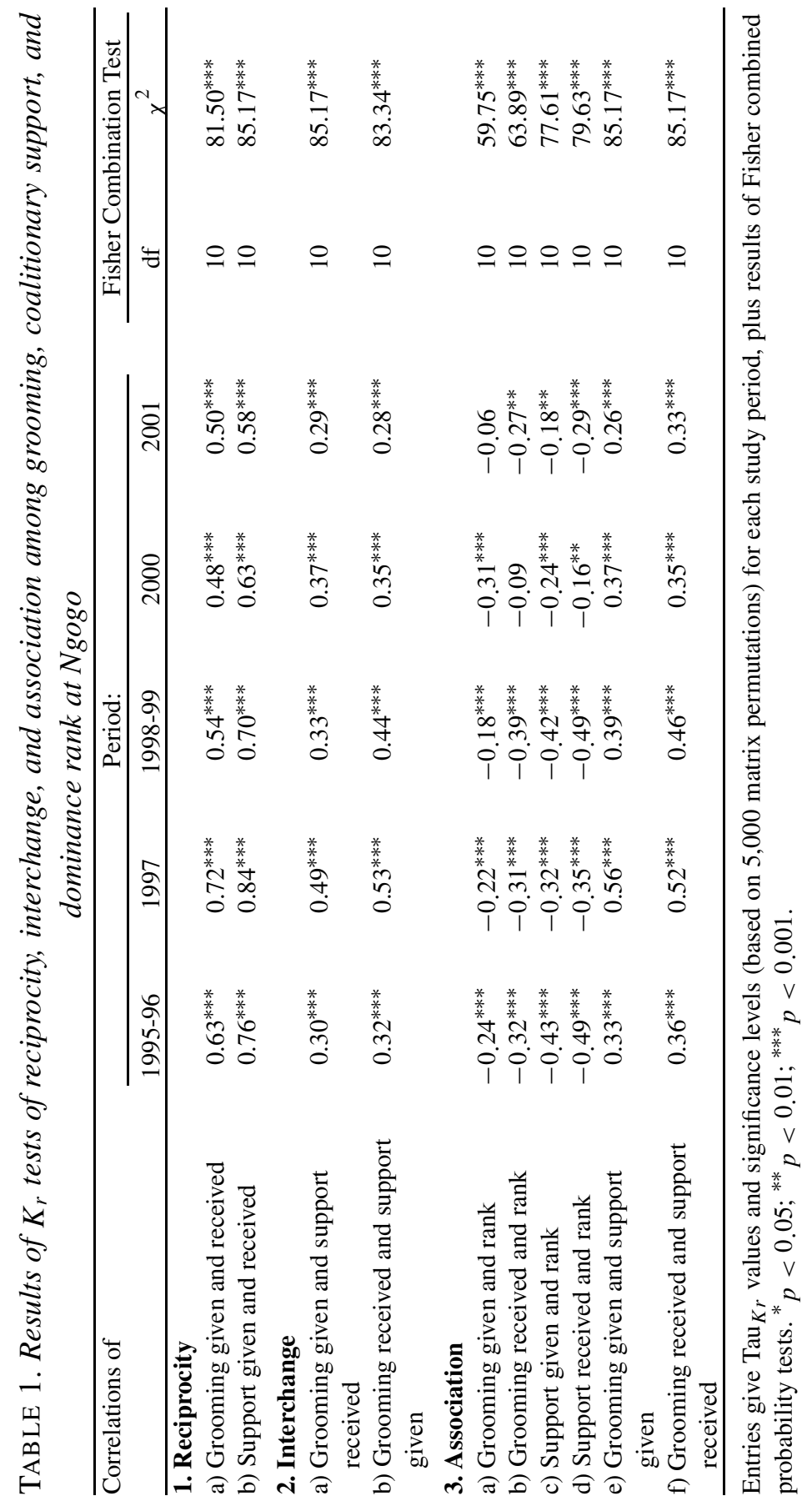




\section{(2) High-ranking males are attractive grooming partners}

Data from 1995-1996 and 1997 were consistent with the hypothesis that high ranking males are attractive grooming partners (Watts, 2000b). Data from subsequent study periods corroborate these results. In all periods except 2001, highly significant negative $\mathrm{Tau}_{K r}$ values show that males groomed high-ranking partners relatively often; the combined probability value was highly significant (Table 1 , result $3 \mathrm{a}$ ). Correlations between grooming received and rank were significant in all study periods except 2000, indicating that high-ranking males received much grooming from others (Table 1 , result $3 b$ ).

\section{(3) Males showed reciprocity in agonistic support}

This hypothesis was confirmed: males also showed highly significant reciprocity in agonistic support at group level in all study periods, and the combined probability value was highly significant (Table 1 , result $1 \mathrm{~b}$ ). That is, the relative frequency with which males supported other was highly correlated with the relative frequency with which they received support from those others. In all study periods, most males did not form coalitions with each other, whereas some others did so occasionally and a few males did so regularly and thus could be considered allies; Fig. 3 illustrates this for 1998-1999. For example, MW and BA were allies in all study periods and each supported the other more often than he supported any other male in most study periods. However, BA had also developed an alliance with HA by 1998-1999; in 2001 coalitions were more common between BA and HA than between BA and $\mathrm{MW}$, and BA and HA each supported the other more than he supported any other male. Conversely, no coalitions occurred between BA and LO or between BA and low-ranking males ST and MI.

\section{(4) High-ranking males were attractive coalition partners}

Results were consistent with this hypothesis. Most coalitions involved males in the upper half of the dominance hierarchy, and significant positive correlations between rank and the frequencies with which males received coalitionary support and with which they supported others held in all study periods (Table 1 , results $3 \mathrm{c}$ and $3 \mathrm{~d}$ ). 


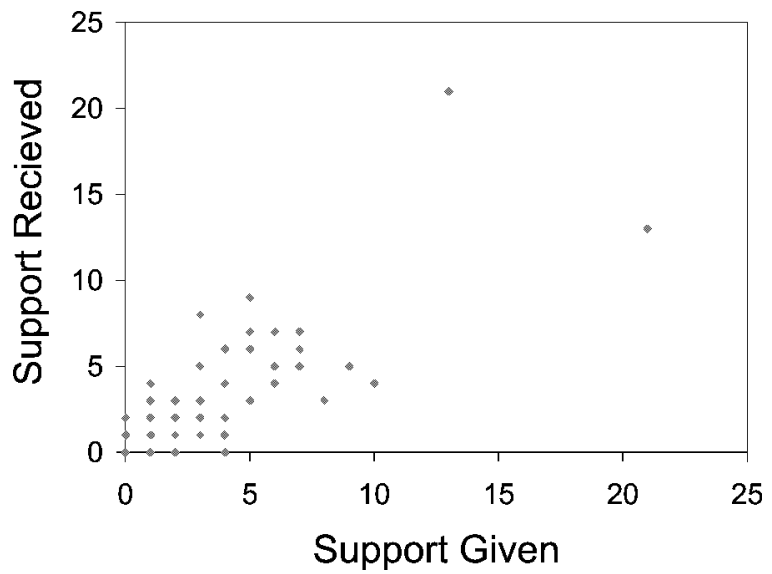

Fig. 3. An example of reciprocity in agonistic support: the relationship between the number of times one member of a male dyad supported the other and the number of times he received support from the other. Data are from the 1998-1999 study period ( $N=24$ adult males). Some data points represent multiple dyads; no support occurred in most dyads. The bivariate plot is for purposes of illustration only; the data were analyzed with non-parametric matrix permutation methods.

\section{(5) Reciprocity in grooming and support was independent of male rank}

This hypothesis was also confirmed. Partial $\mathrm{Tau}_{K r}$ values indicated that the correlation between grooming given and grooming received, and that between agonistic support given and received, were still significant with male dominance ranks controlled (Table 2, results 1 and 2). Thus reciprocity in grooming and support occurred independently of the attraction to highranking partners.

(6) Males interchange grooming and support, independently of rank effects and of associations between grooming and support given and between grooming and support received

In all study periods, correlations between grooming given and support received were positive and highly significant (Table 1, result 2a). Figure 4 illustrates this for 1998-1999, and again indicates that neither male supported the other in most dyads, whereas some dyads stood out because one member commonly groomed the other, from whom he received support relatively often (e.g. MW and BA; HA and EL; HA and BA). Similarly, correlations between grooming received and support given were positive and highly 


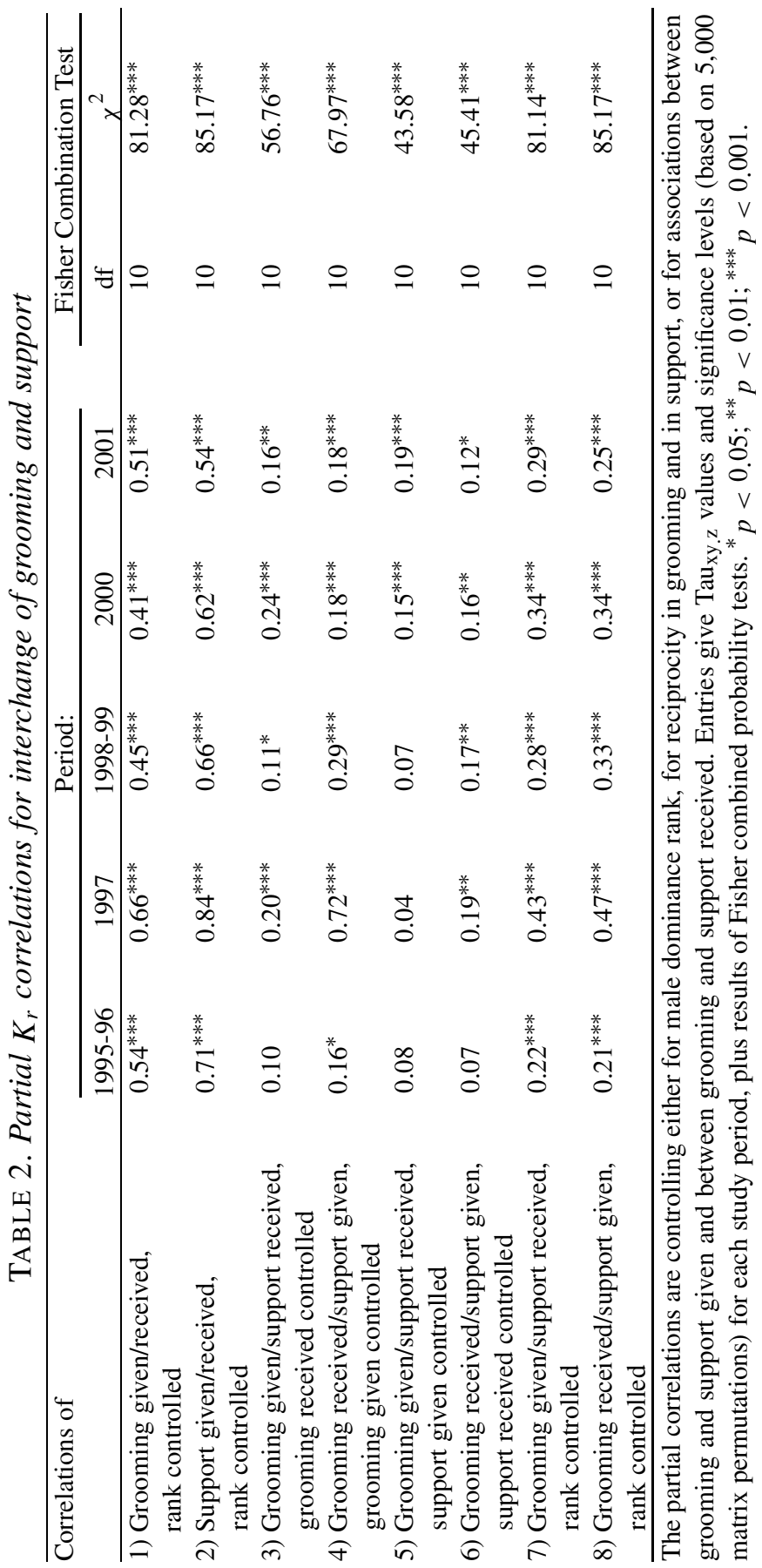




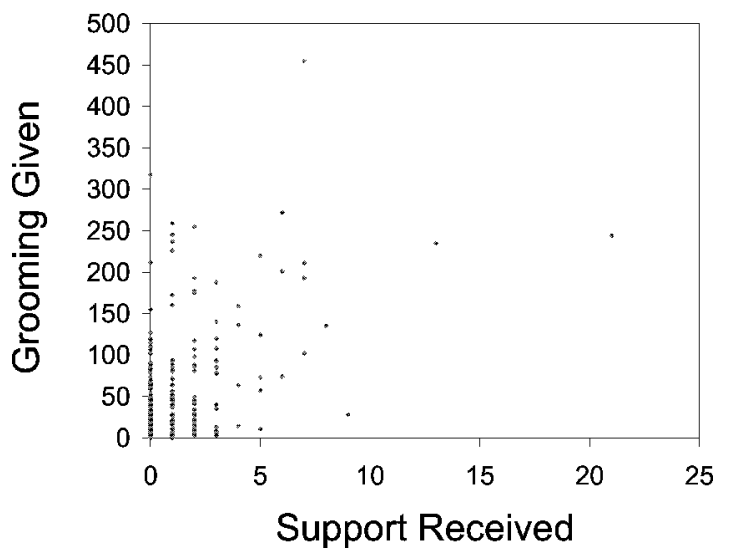

Fig. 4. An example of interchange of grooming given and support received: the relationship between the amount of grooming (in minutes) one member of a male dyad gave to the other to the number of times he received agonistic support from the other. Data are from the 19981999 study period ( $N=24$ adult males). Each symbol represents one dyad; most dyads had values of zero for support. The bivariate plot is for purposes of illustration only; the data were analyzed with non-parametric matrix permutation methods.

significant in all periods (Table 1 , result 2 b). Combined probability values were highly significant in both cases.

In all study periods, the amount of grooming given was also positively and significantly correlated with the amount of support given (Table 1, result 3e; Fig. 5). Significant positive correlations between the amount of grooming received and the amount of support received also occurred in all periods (Table 1 , result $3 \mathrm{f}$ ). These findings raise the possibility that the apparent interchange of grooming and support was a byproduct of grooming reciprocity combined with a tendency of individuals to support those partners whom they also often groomed ( $c f$. Hemelrijk, 1990a). However, partial $K_{r}$ tests showed that the positive correlations between grooming given and support received were still significant when grooming received was controlled, and that the positive correlations between grooming received and support given were still significant with grooming given controlled, in all study periods (Table 2, results 3 and 4).

The apparent interchange of grooming and support might instead have been a byproduct of reciprocity in support combined with a tendency of individuals often to groom those whom they often supported. Partial $K_{r}$ tests showed that in all study periods, the partial correlations between grooming given and support received were positive when support given 


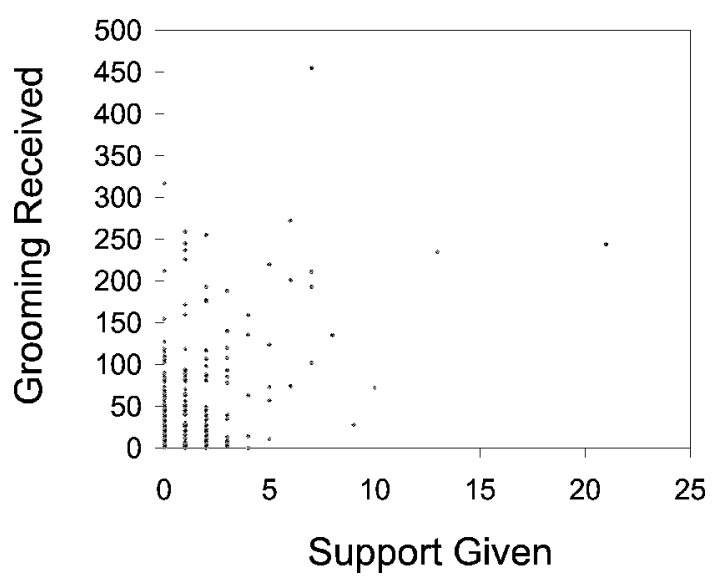

Fig. 5. An example of interchange of grooming received and support given: the relationship between the number of times one member of a male dyad gave agonistic support to the other to the amount of grooming (in minutes) he received from the other. Data are from the 19981999 study period ( $N=24$ adult males). Each symbol represents one dyad; most dyads had values of zero for support. The bivariate plot is for purposes of illustration only; the data were analyzed with non-parametric matrix permutation methods.

was controlled. Only the values for 2000 and 2001 ware significant, but the combined probability value was significant (Table 2, result 5). Partial correlations between grooming received and support given were positive with support received controlled in all study periods and were significant in all periods except 1995-1996 (Table 2, result 6). In this case also, the combined probability across study periods was significant (Table 2, result 6).

Nor was the apparent interchange of grooming and support an artifact of the relationships between both of these variables and male dominance ranks. Correlations between grooming given and support received, and between grooming received and support given, were also still significant with dominance rank controlled (Table 2, results 7 and 8).

\section{(7) Males use grooming to gain tolerance from or to appease other males}

Males may use grooming to lower the amount of aggression they receive, especially from others who outrank them or with whom they do not have decided dominance relationships and who are not their allies. Avoiding aggression could allow males to minimize stress and perhaps give them better access to good feeding sites, estrous females, and other social partners. Potential aggressors receive hygienic and perhaps other physiological benefits 
TABLE 3. Association of grooming and aggression

\begin{tabular}{lcc}
\hline Correlations of: & \multicolumn{2}{c}{ Period: } \\
\cline { 2 - 3 } & 2000 & 2001 \\
\hline 1) Aggression received/grooming given & $-0.17^{* *}$ & 0.08 \\
2) Aggression given/grooming received & 0.07 & $0.29^{* * *}$ \\
3) Aggression received/grooming given, grooming & $-0.20^{* * *}$ & $0.18^{* *}$ \\
$\quad$ received controlled & $-0.12^{*}$ & $0.12^{*}$ \\
4) Aggression received/grooming given, support & & $0.28^{* * *}$ \\
$\quad$ received controlled & -0.09 & \\
5) Aggression given/grooming received, grooming & & $0.27^{* * *}$ \\
$\quad$ given controlled & 0.03 & \\
6) Aggression given/grooming received, & &
\end{tabular}

Entries give results of $K_{r}$ tests for association between grooming given and aggression received, and between grooming received, and aggression given, and of partial $K_{r}$ tests analyzing these associations with either or grooming received, grooming given, or agonistic support controlled. Results are based on 5,000 permutations. Data are from the 2000 and 2001 study periods only. ${ }^{*} p<0.05$; $^{* *} p<0.01$; $^{* *} p<0.001$.

from grooming, and may be less inclined to direct aggression at otherwise low value partners who groom them often. I used the 2000 and 2001 data sets to test three predictions of the tolerance hypothesis: (a) grooming given and aggression received were negatively correlated; (b) grooming received was negatively correlated with aggression given; and (c) these relationhips were independent of reciprocity in grooming and of how often males formed coalitions.

No clear support for the tolerance hypothesis emerges. Many results were inconsistent with predictions, although data from 2000 supported the prediction that the amount of grooming given was inversely correlated with the amount of aggression received (Table 3, result 1). This correlation remained significant with grooming received controlled (Table 3, result 3) and with support received controlled (Table 3, result 4), indicating that it was not a byproduct of reciprocity in grooming or interchange of support and grooming. In contrast, though, the correlation between aggression received and grooming given was positive in 2001, although not quite significant ( $p=0.10$; Table 3 , result 1$)$. That is, males tended to receive aggression relatively often from those they groomed relatively often. This relationship still held with the effects of support received partialled out (Table 3, result 4). However, controlling for reciprocity in grooming gives some support to the tolerance hypothesis: the partial correlation between aggression received and 
grooming given with grooming received partialled out was significant, but negative (Table 3, result 3). This suggests that in dyads in which grooming was relatively common but in which one male did most or all of it, that male received relatively low levels of aggression from the male he groomed.

Contrary to predictions, correlations between aggression given and grooming received were positive in both study periods. The correlation was nonsignificant for 2000 ( $p<0.10$; Table 3, result 2 ); partial correlations between these two variables were non-significant with grooming received partialled out and with support received partialled out (Table 3, results 5 and 6). The correlation was significant for 2001 (Table 3, result 2): males behaved aggressively relatively often to males who groomed them relatively often. Partial correlations between these variables with either grooming received or support given controlled were also significantly positive (Table 3 , results 5 and 6).

\section{(8) Results of previous studies at Ngogo}

Three previous studies have explicitly addressed questions about reciprocity and interchange among males. Mitani et al. (2000), analyzing a less extensive database, also found group-level reciprocity in agonistic support. Males also show reciprocity in meat sharing (Mitani \& Watts, 1999, 2001) and interchange of meat and agonistic support (Mitani \& Watts, 2001).

Several other studies have included relevant analyses of relationships between social variables, or between social and demographic variable, without explicitly addressing the issue of social exchange. One (Watts \& Mitani, 2001) concerned boundary patrolling, a striking example of cooperation among males. Probably because so many of them are present at Ngogo, males there patrol more often and in larger groups than those at Gombe and at Taï (Watts \& Mitani, 2001). Nevertheless, significant variation in the frequency with which individual males patrol exists, and patrol composition varies markedly. The frequency with which male dyads participate in patrols together is positively and significantly correlated with the total amount of grooming per dyad and with the frequency of coalitions per dyad. It is also positively and significantly correlated with the number of times that males jointly participate in hunts of red colobus monkeys (ibid.).

Mitani et al. (2000) examined the relationship between potential maternal relatedness and several social variables, and Mitani et al. (in press) have 
replicated these analyses with a more extensive data set and also examined the influence of similarity in age on social variables. The results indicate that males relatively close in age are more likely to associate in parties, remain in close proximity, groom and share meat with each other, form coalitions, and participate in patrols together than males far apart in age. In contrast, maternal relatedness seems to have no consistent social effects.

\section{Discussion}

The more extensive analyses reported here corroborate several earlier findings concerning among males at Ngogo. Reciprocity in grooming occured at group-level (cf. Watts, 2000a), males disproportionately directed grooming up the dominance hierarchy, and high ranking males received more grooming than lower ranking males ( $c f$. Watts, 2000b). These rank effects are expected if high-ranking males, because they are effective allies, are attractive grooming partners. Results given here also corroborate and extend an earlier report of group-level reciprocity in coalition formation (Mitani et al., 2000). They also show that males interchanged grooming and agonistic support at group level, something not previously documented for wild chimpanzees. Significant relationships between grooming given and support received, and between grooming received and support given, were independent of reciprocity in grooming and in support. They were also independent of rank effects on grooming and on support given, and were independent of significant associations between grooming given and support given and between grooming received and support received.

These results add to other evidence that reciprocity is prominent in chimpanzee social behavior, although not universally present. For example, Mitani \& Watts (1999; cf. Mitani \& Watts, 2001) found reciprocity in meat sharing among males at Ngogo, de Waal (1989) found reciprocity in food sharing among captive chimpanzees at Yerkes, and de Waal \& Luttrell (1988) found reciprocity in support among captive chimpanzees at Arnhem. Hemelrijk \& Ek (1991) replicated this last finding, but only for periods with no clear alpha male; group level reciprocity was not evident when the group had a well-established alpha. Vervaecke et al. (2000) found reciprocity in support in a captive group of bonobos (Pan paniscus), the sister species of chimpanzees. However, this seemed to be a byproduct of strong correlations 
between support and rank: individuals mostly supported high-ranking group members, who often supported others. Reciprocity in support at Ngogo was independent of significant positive correlations between rank and the frequencies of giving and of receiving support.

Evidence for interchange in chimpanzees and bonobos has been sparser than that for reciprocity. Chimpanzees at Yerkes were more likely to share food with others after being groomed by them (De Waal, 1989). Grooming given and support received by males were significantly correlated at Arnhem, but this was due to reciprocity in grooming combined with an association between grooming received and support received (Hemelrijk \& Ek, 1991). The correlation between grooming received and support given was nonsignificant. However, females genuinely appeared to interchange grooming given and support received (ibid.). Vervaecke et al. (2000) found a significant correlation between grooming given and support received in their bonobo group, but this became non-significant when they controlled for the effects of rank: high-ranking group members were frequent targets for grooming, and they often supported others. At Ngogo, interchange between grooming and support was still significant with rank effects, grooming reciprocity, and associations between grooming given and support given, or between grooming received and support received, taken into account.

Vervaecke et al.'s (2000) results are not directly comparable to those from Ngogo, because their study group had only one adult male and they included adult females and adolescent males in their analyses. Indeed, when they controlled for the effects of sex or age, the partial correlations of grooming given with support received were also non-significant. Otherwise, one implication of the conflicting results from investigations of interchange is that not all variation in chimpanzee grooming and coalition formation results from market effects. Allogrooming can serve multiple functions and its hygienic effects and any calming effects are valuable in themselves (Dunbar, 1991; Cords, 1997; Henzi \& Barrett, 1999; Barrett et al., 2000), so we should not expect that males necessarily exchange grooming for any other social acts or for any material benefits.

Relationship histories and variation in social tactics also influences variation in grooming. Male MZ was a notable case in point. He was clearly the oldest male in the Ngogo community and subordinate to almost all others when he died in 2000. He groomed with 17 of 23 other adult males during 1998-1999 and received more grooming than he gave in 13 of 17 dyads. He 
also was one of the most successful males at getting meat from others (Watts \& Mitani, 2002). But those who groomed him and gave him meat did so with no prospect of agonistic support or meat in return: he no longer participated in coalitions or actively hunted. He might have been an important ally for many younger males before we started work at Ngogo, but he was certainly not a valuable social partner during the time considered here, in so far as value depends on provision of agonistic support and meat. Occasional dyads in which high-ranking males groomed low-ranking males relatively often, but did not form coalitions with them, might have represented prospective allies. In 2001, for example, high-ranking male EL often groomed GA, a young male who, while still low-ranking, had risen considerably in rank and become much more assertive over the previous year.

Male chimpanzees compete for alliance partners (de Waal, 1982, 1984; Nishida, 1983; Goodall, 1986; Nishida \& Hosaka, 1996; Watts, unpubl. data). Seyfarth's (1977) model of attraction to high rank generates the additional prediction that competition for effective allies leads to concentration of grooming among closely ranked partners; Ngogo data are consistent with this prediction (Watts, 2000b). Grooming can help partners to develop familiarity and trust and to convey information about willingness to engage in other sociopositive interactions. It can thus simultaneously be investment in a social relationship and a sign of willingness to continue or increase that investment (Seyfarth, 1977, 1980; Dunbar, 1988, 1991; Cords, 1997; Henzi et al., 2000). This logic underlies the argument that grooming can increase the willingness of others, particularly non-relatives, to provide support in agonistic interactions with third parties, although grooming and extensive familiarity are not always necessary for alliance formation. For example, male savanna baboons (Papio cynocephalus) do not groom with each other (although they can negotiate about cooperation by other means), and form alliances that depend more on combined agonistic power than on familiarity (Noë, 1990; Noë \& Sluijter, 1995). The relative power of potential allies is also important to male chimpanzees, as is assessment of the other options that potential partners and rival have, and networks of coalition formation and affiliation are not always congruent (de Waal, 1978, 1982, 1984).

The only clear support that the analyses above gave to the hypothesis that grooming others induced tolerance was the significant negative relationship between grooming given and aggression received in the 2000 study period. However, simply examining aggression frequency is an inadequate test of 
this hypothesis. Chimpanzees commonly use grooming to reconcile (de Waal \& van Roosmalen, 1979). Males at Ngogo often groom other males after receiving aggression from them (pers. observ.), although whether this decreases the likelihood of further aggression is presently unknown. Also, large imbalances in grooming within dyads and of increases in grooming during periods of heightened tension between males who are rivals, not allies (de Waal, 1982; pers. observ.), suggest that male chimpanzees can use grooming to induce tolerance and to reduce social uncertainty. If so, individuals may sometimes groom others with no requirement for grooming or coalitionary support in return. In some Ngogo dyads (e.g. ML and MW; ST and CO), low-ranking males groomed high-ranking males but received little or no grooming, no agonistic support, and no meat in return; the tolerance hypothesis might have applied to these cases. De Waal \& Luttrell (1986) found that low-ranking female rhesus macaques (Macaca mulatta) received frequent opposition in polyadic aggression from highranking females whom they often groomed. They suggested that had the low-ranking females groomed their higher-ranking partners less, they would have received even more aggression ( $c f$. Kapsalis \& Berman (1996)). The positive relationship between grooming given and aggression received in the 2001 data set from Ngogo might have reflected something similar (grooming given and opposition received were also positively correlated; Watts, unpubl. data).

High-ranking individuals can sometimes obtain hygienic and physiological benefits by demanding grooming from subordinates without grooming them or offering support (Schino, 2001). This sometimes happens among adult males at Ngogo, and adults often command grooming from adolescents (pers. observ.). More detailed analyses of grooming at the dyadic level will show whether is common in dyads far apart in rank, but not those closer in rank and not those of allies. It will also show whether especially marked asymmetries in grooming characterize dyads separated by large rank distances, with subordinate partners giving more grooming than they receive.

At the same time, the grooming-for-support hypothesis would be strengthened by findings that within-dyad grooming reciprocity is relatively high for allies and that high-ranking males sometimes groom subordinate allies more than the reverse (as was true for alpha male MW and his then-ally RU in 1996 and 1997). Hohmann et al. (1999) found that within-dyad grooming 
reciprocity was higher for wild bonobos who were close associates than for those who associated randomly or less than expected by chance; the close associates category included individuals who formed coalitions.

Various researchers have pointed out that support in contests may reflect social bonds: some individuals often stay in close proximity, groom with each other, and otherwise engage in affiliative interactions, and they aid each other against third parties. For example, Hemelrijk \& Ek (1991) argued that two findings reflected social bonds at Arnhem. One was the significant association between support given and grooming given among males. The second was that a positive association between support given and grooming given, combined with reciprocity in grooming, accounted for the correlation between support given and grooming received among females. Matheson \& Bernstein (2001) take a stronger position and contrast the 'social bond' hypothesis with the grooming-for-support hypothesis as if they are mutually exclusive. However, this need not be the case. Social bonds presumably reflect shared interests, whether due to sharing of alleles identical by descent or, more broadly, to the potential benefits of cooperating against 'environmental challenges' like competing groups or sub-groups of conspecifics (ibid.). Yet interchange also reflects shared interests, and the contrast with social bonding seems to hinge on the assumption that exchange of agonistic support and interchange of grooming and support are examples of reciprocal altruism. A growing body of evidence instead points to mutualism as the explanation for much agonistic aiding in nonhuman primates. For example, the payoffs to coalitionary mate guarding by males at Ngogo fit the pattern expected from mutualism (Watts, 1998). Also, Hemelrijk \& Ek (1991) argued that many coalitions between male chimpanzees at Arnhem during periods with no clear alpha male resulted from male opportunism and did not depend on reciprocity: males seized chances to score victories against outnumbered rivals. A similar argument applies to non-kin support among females in resident-nepotistic cercopithecines (Chapais, 1992; $c f$. Chapais et al., 1995) and to males in some of the same species. For example, Widdig et al. (2000) found group-level statistical reciprocity in coalition formation among male barbary macaques (Macaca sylvanus), but also found that most interventions in contests were by mid- and high-ranking males who outranked both opponents and therefore faced little risk of retaliation. This behavior could help the interveners to maintain their own ranks and would not require future repayment because it does not impose net costs (ibid.). Similar risk avoidance 
occurs in rhesus (Bernstein \& Ehardt, 1985) and bonnet macaques (Macaca radiata; Silk, 1993). Formation of low-risk coalitions in which all participants stand to make immediate net gains is widespread in primates and may even incorporate much presumed 'altruism' among kin (Chapais, 2001).

Male chimpanzees follow mixed strategies of agonistic aiding, and benefiting from these may sometimes, but not always, depend on interchange of grooming for support and reciprocity in support. Risk generally seemed low for coalition participants at Ngogo. Coalitions in which partners targeted males who outranked them both were uncommon. Most involved partners who both outranked their targets. When males participated in coalitions against opponents who outranked them, they usually did so with a partners or partners who outranked those opponents. These common cases seemed to represent exploitation of low-cost opportunities to reinforce or to gain dominance over outnumbered opponents in situations where immediate retaliation was unlikely. Repayment in support or grooming might have been unimportant, unless one or both coalition partners depended on the other to maintain dominance over their target. Likewise, social bonds might or might not have been in play. Polyadic aggression that involved males who lacked clear dominance relationships often seemed to involve attempts by the aggressors to establish dominance over their targets. The circumstances might usually have been relatively safe because the opponents were outnumbered, but willingness to reciprocate or to trade grooming for support might have been more relevant, especially if the partners also were close or equal in rank. Lengthy challenges that involve alliances also occur. These carry some potential for costly retaliation or for punishment (de Waal, 1982; Nishida \& Hosaka, 1996), and they may require reciprocity. For an alpha male to retain his position, and for other high-ranking males in a community as large as that at Ngogo to retain their ranks, may also require reciprocal support and grooming. Males at Ngogo and elsewhere make tactical switches among allies when this is advantageous and use grooming to solidify alliances and to enlist new partners (de Waal, 1978, 1982; Goodall, 1986; Nishida \& Hosaka, 1996; Watts, unpubl. data). Grooming helps males to maintain their social bonds ( $c f$. Matheson \& Bernstein, 2000), but willingness to cooperate against third parties - especially to challenge third parties whose fighting ability may outweigh that of either ally — is also part of a social bond. When males stand to lose the benefits of cooperation because partners desert them, their ability to offer services in biological markets becomes important. 


\section{References}

Barrett, L., Henzi, S.P., Weingrill, T., Lycett, J.E. \& Hill, R.A. (1999). Market forces predict grooming reciprocity in female baboons. - Proc. Royal Soc., London, Series B 266, p. 665-670.

Bernstein, I.S. \& Erhardt, C.L. (1985). Agonistic aiding: kinship, rank, age, and sex influences. - Amer. J. Primatol. 8, p. 37-52.

Biro, D. \& Matsuzawa, T. (2001). Chimpanzee numerical competence: cardinal and ordinal skills. - In: Primate origins of human cognition and behavior (T. Matsuzawa, ed.). Springer Verlag, Tokyo-Berlin-Heidelberg-New York, p. 199-225.

Boesch, C. (1994). Cooperative hunting in wild chimpanzees. - Anim. Behav. 48, p. 653667.

— — \& Boesch, H. (1989). Hunting behavior of wild chimpanzees in the Tai National Park. - Am. J. Phys. Anthropol. 78, p. 547-573.

— — \& Boesch-Achermann, H. (2000). The chimpanzees of the Tai forest. — Oxford University Press, Oxford.

Boysen, S. (1997). Representation of quantities by apes. — Adv. Study Behav. 26, p. 435-462.

Butynski, T. (1990). Comparative ecology of blue monkeys (Cercopithecus mitis) in highand low-density subpopulations. - Ecol. Monogr. 60, p. 1-26.

Chapais, B. (1992). The role of alliances in the social inheritance of rank among female primates. - In: Coalitions and alliances in humans and other animals (A.H. Harcourt \& F.B.M. de Waal, eds). Oxford University Press, Oxford, p. 29-60.

- - (2001). Primate nepotism: what is the explanatory value of kin selection? - Intl. J. Primatol. 22, p. 203-229.

— - , Gauthier, C. \& Prud'homme, J. (1995). Dominance competition through affiliation and support in Japanese macaques: an experimental study. — Intl. J. Primatol. 16, p. 521536.

Cheney, D.L. \& Seyfarth, R.M. (1990). How monkeys see the world. - University of Chicago Press, Chicago.

Constable, J.E., Ashley, M.V., Goodall, J. \& Pusey, A.E. (2001). Noninvasive paternity assignment in Gombe chimpanzees. - Molec. Ecol. 10, p. 1279-1300.

Cords, M. (1997). Friendships, alliances, reciprocity and repair. — In: Machiavellian intelligence II: extensions and evaluations (A. Whiten \& R.W. Byrne, eds). Cambridge University Press, Cambridge, p. 24-49.

Dunbar, R.I.M. (1988). Primate social systems. — Cornell University Press, New York.

— - (1991). Functional significance of social grooming in primates. — Folia primatol. 57, p. 121-131.

Goldberg, T.L. \& Wrangham, R.W. (1997). Genetic correlates of social behavior in wild chimpanzees: evidence from mitochondrial DNA. - Anim. Behav. 54, p. 559-570.

Goodall, J. (1986). The chimpanzees of Gombe. — Harvard University Press, Cambridge.

Harcourt, A.H. (1989). Social influences on competitive ability: alliances and their consequences. - In: Comparative socioecology (V. Standen \& R. Foley, eds). Blackwell, London, p. 223-242.

- - (1992). Coalitions and alliances: are primates more complex than non-primates? In: Coalitions and alliances in humans and other animals (A.H. Harcourt \& F.B.M. de Waal, eds). Oxford University Press, Oxford, p. 445-471. 
Herbiger, I., Boesch, C. \& Rothe, H. (2001). Territory characteristics among three neighboring chimpanzee communities in the Taï National Park, Côte d'Ivoire. - Intl. J. Primatol. 22, p. 143-167.

Hemelrijk, C.K. (1990a). Models of, and tests for, reciprocity, unidirectionality, and other social interaction patterns at group level. - Anim. Behav. 39, p. 1023-1029.

- _ (1990b). A matrix partial correlation test used in investigations of reciprocity and other social interaction patterns at a group level. - J. theor. Biol. 143, p. 405-420.

— — \& Ek, A. (1991). Reciprocity and interchange of grooming and 'support' in captive chimpanzees. - Anim. Behav. 41, p. 923-935.

— —, von Laere, G.J. \& van Hooff, J.A.R.A.M. (1992). Sexual exchange relationships in captive chimpanzees? - Behav. Ecol. Sociobiol. 30, p. 269-275.

— - Meier, C. \& Martin, R.D. (1999). 'Friendship' for fitness in chimpanzees? — Anim. Behav. 58, p. 1223-1229.

Henzi, S.P. \& Barrett, L. (1999). The value of grooming to female primates. — Primates 40, p. 47-59.

Hiraiwa \& Hiaraiwa-Hasegawa, M. (1990). Sperm competition and mating behavior. — In: The chimpanzees of the Mahale Mountains (T. Nishida, ed.). Tokyo University Press, Tokyo, p. 115-132.

Hohmann, G., Gerloff, U., Tautz, D. \& Fruth, B. (1999). Social bonds and genetic ties: kinship, association, and affiliation in a community of bonobos (Pan paniscus). Behaviour 136, p. 1219-1235.

van Hooff, J.A.R.A.M. \& van Schaik, C.P. (1994). Male bonds: affiliative relationships among nonhuman primate males. - Behaviour 130, p. 309-337.

Kapsalis, E. \& Berman, C.M. (1996). Models of affiliative relationships among free-ranging rhesus monkeys (Macaca mulatta). II. Testing predictions for three hypothesized organizing principles. - Behaviour 133, p. 1235-1263.

Kummer, H. (1978). On the value of social relationships to nonhuman primates: a heuristic scheme. - Soc. Sci. Inform. 17, p. 687-705.

Matheson, M.D. \& Bernstein, I.S. (2000). Grooming, social bonding, and agonistic aiding in rhesus monkeys. - Amer. J. Primatol. 51, p. 177-186.

Mitani, J. \& Watts, D.P. (1999). Demographic influences on the hunting behavior of chimpanzees. - Amer. J. Phys. Anthropol. 109, p. 439-454.

— — \& - - (2001). Why do chimpanzees hunt and share meat? - Anim. Behav. 61, p. $915-924$.

— - Hunley, K.L. \& Murdoch, M.E. (1999). Geographic variation in the calls of wild chimpanzees: a reassessment. - Amer. J. Primatol. 47, p. 133-151.

— - Merriwether, D.A. \& Zhang, C. (2000). Male affiliation, cooperation, and kinship in wild chimpanzees. - Anim. Behav. 59, p. 885-893.

- —, Watts, D.P., Pepper, J.W. \& Merriwether, D.A. (in press). Demographic and social constraints on male chimpanzee behaviour. - Anim. Behav.

Newton-Fisher, N.E. (1999). Association by male chimpanzees: a social tactic? — Behaviour 136, p. 705-730.

Nishida, T. (1968). The social group of wild chimpanzees in the Mahale Mountains. Primates 9, p. 167-224.

- - (1983). Alpha status and agonistic alliance in wild chimpanzees (Pan troglodytes schweinfurthii). — Primates 24, p. 318-336. 
—— \& Hiraiwa-Hasegawa, M. (1987). Chimpanzees and bonobos: cooperative relationships among males. - In: Primate societies (B.B. Smuts, D.L. Cheney, R.M. Seyfarth, R.W. Wrangham \& T.T. Struhsaker, eds). University of Chicago Press, Chicago, p. 165-178.

—— \& Hosaka, K. (1996). Coalition strategies among adult male chimpanzees of the Mahale Mountains, Tanzania. - In: Great ape societies (W.C. McGrew, L.F. Marchant \& T. Nishida, eds). Cambridge University Press, Cambridge, p. 114-134.

Noe, R. (1990). A veto game played by baboons: a challenge to the use of the prisoner's dilemma as a paradigm for reciprocity and cooperation. - Anim. Behav. 39, p. 78-90.

— - (1992). Alliance formation among male baboons: shopping for profitable partners. In: Coalitions and alliances in humans and other animals (A.H. Harcourt \& F.B.M. de Waal, eds). Cambridge University Press, Cambridge, p. 285-321.

_ — \& Hammerstein, P. (1994). Biological markets: supply and demand determine the effect of partner choice in cooperation, mutualism, and mating. — Behav. Ecol. Sociobiol. 35, p. 1-11.

— —, van Schaik, C.P. \& van Hooff, J.A.R.A.M. (1991). The market effect: an explanation for payoff asymmetries among collaborating animals. - Ethology 87, p. 97-118.

— — \& Sluijter, A.A. (1995). Which adult male savanna baboons form coalitions? — Intl. J. Primatol. 16, p. 77-106.

Pepper, J., Mitani, J.C. \& Watts, D.P. (1999). General gregariousness and specific partner preference among wild chimpanzees. - Intl. J. Primatol. 20, p. 613-632.

Perry, S. (1996). Female-female social relationships in wild white-faced capuchin monkeys, Cebus capucinus. - Amer. J. Primatol. 40, p. 167-182.

Pusey, A.E. (2000). Of apes and genes: chimpanzee social organization and reproduction.-

In: Tree of origin (F.B.M. de Waal, ed.). Harvard University Press, Cambridge, p. 9-37.

Schino, G. (2001). Grooming, competition, and social rank among female primates: a metaanalysis. - Anim. Behav. 62, p. 265-271.

Seyfarth, R.M. (1977). A model of social grooming among adult female monkeys. — J. theor. Biol. 65, p. 671-698.

- - (1980). The distribution of grooming and related behaviours among adult female vervet monkeys. - Anim. Behav. 28, p. 798-813.

Silk, J.B. (1993). Does participation in coalitions influence dominance relationships among male bonnet macaques? - Behaviour 126, p. 171-189.

— - Seyfarth, R.M. \& Cheney, D.L. (1999). The structure of social relationships among female savanna baboons in Moremi Reserve, Botswana. - Behaviour 136, p. 679-703.

Sokal, R.R. \& Rolf, F.J. (1995). Biometry. - W.H. Freeman, San Francisco.

Stanford, C. (1998). Chimpanzee and red colobus: The ecology of predator and prey. Harvard University Press, Cambridge, Mass.

Sterck, E., Watts, D.P. \& van Schaik, C.P. (1997). The evolution of social relationships in female primates. - Behav. Ecol. Sociobiol. 41, p. 291-309.

Struhsaker, T.T. (1997). Ecology of an African rain forest. - University Presses of Florida, Gainesville, Florida.

Tutin, C. (1979). Mating patterns and reproductive strategies in a community of wild chimpanzees (Pan troglodytes schweinfurthii). - Behav. Ecol. Sociobiol. 6, p. 29-38.

Vervaecke, H., deVries, H. \& van Elsacker, L. (2000). The pivotal role of rank in grooming and support behaviour in a captive group of bonobos (Pan paniscus). - Behaviour 137, p. 1463-1485. 
de Waal, F.B.M. (1978). Exploitative and familiarity-dependentsupport strategies in a colony of semi-free living chimpanzees. - Behaviour 66, p. 268-312.

— - (1982). Chimpanzee politics. — Johns Hopkins University Press, Baltimore.

- - (1984). Sex differences in the formation of coalitions among chimpanzees. — Ethol. Sociobiol. 5, p. 239-255.

— - (1989). Food sharing and reciprocal obligations in chimpanzees. — J. Human Evol. 18, p. 433-459.

— — \& Lutrell, L. (1986). The similarity principle underlying social bonding among female rhesus monkeys. - Folia primatol. 46, p. 215-234.

- — \& - - (1988). Mechanisms of social reciprocity in three primate species: symmetrical relationship characteristics or cognition? - Ethol. Sociobiol. 9, p. 101-118.

— — \& van Roosmalen, M. (1979). Reconciliation and consolation among chimpanzees. Behav. Ecol. Sociobiol. 5, p. 55-66.

Watts, D.P. (1998). Coalitionary mate guarding by male chimpanzees at Ngogo, Kibale National Park, Uganda. — Behav. Ecol. Sociobiol. 44, p. 43-55.

- - (2000a). Grooming between male chimpanzees at Ngogo, Kibale National Park, Uganda. I. Partner number and diversity and reciprocity. - Intl. J. Primatol. 21, p. 189210 .

- - (2000b). Grooming between male chimpanzees at Ngogo, Kibale National Park, Uganda. II. Male rank and priority of access to partners. - Intl. J. Primatol. 21, p. 211238.

— — \& Mitani, J.C. (2000). Infanticide and cannibalism by male chimpanzees at Ngogo, Kibale National Park, Uganda. — Primates 41, p. 357-364.

- - \& - - (2001). Boundary patrols and intergroup encountersin wild chimpanzees. Behaviour 138, p. 299-327.

— — \& - - (2002). Hunting by chimpanzees at Ngogo, Kibale National Park, Uganda. — Int. J. Primatol. 23.

- — \& - - (in press). Hunting and meat sharing by chimpanzees at Ngogo, Kibale National Park, Uganda. - In: Behavioral diversity in chimpanzees and bonobos (G. Hohmann \& C. Boesch, eds). Cambridge University Press, Cambridge.

Widdig, A., Streich, W.J. \& Tembrock, G. (2000). Coalition formation among male barbary macaques. (Macaca sylvanus). — Amer. J. Primatol. 50, p. 37-51.

Woodruff, G. \& Premack, D. (1981). Primitive mathematical concepts in the chimpanzee: proportionality and numerosity. - Nature 293, p. 568-570.

Wrangham, R.W. (1979). On the evolution of ape social systems. - Social Sci. Information 18 , p. 335-368.

— — (1999). Evolution of coalitionary killing. — Yrbk. Phys. Anthro. 42, p. 1-30. 